\title{
Effects of mixture formation strategies on combustion in dual-fuel engines - a review
}

The article presents an overview of technical solutions for dual fuel systems used in internal combustion engines. It covers the historical and contemporary genesis of using two fuels simultaneously in the combustion process. The authors pay attention to the value of the excess air coefficient in the cylinder, as the ignitability of the fuel dose near the spark plug is a critical factor. The mixture formation of compression ignition based systems are also analyzed. The results of research on indirect and direct injection systems (and their combinations) have been presented. Research sections were separated based to the use of gasoline with other fuels or diesel oil with other fuels. It was found that the use of two fuels in different configurations of the fuel supply systems extends the conditions for the use of modern combustion systems (jet controlled compression ignition, reactivity controlled compression ignition, intelligent charge compression ignition, premixed charge compression ignition), which will enable further improvement of combustion efficiency.

Keywords: dual fuel engine, excess air coefficient, multi-fuel mixture forming

\section{Introduction}

Combustion engines are the key element in global transport nowadays. Since decades they have been subjected to improvements, which increase their efficiency. One of the development path of this power source is the research on supplying them with different fuels.

The main aim of this article is to put together the dual fuel technology applications and their critical review.

The overview has been divided into three groups:

- historical solutions using dual fuel supply,

- modern dual fuel systems in a mixed configuration (using both direct and indirect injection),

- modern dual fuel systems using a direct injection only.

In this review the main emphasis was put on the excess air coefficient value inside a combustion chamber. The overview contains the results of author's original research concerning dual direct injection system supplying various light hydrocarbon fuels.

\section{The history of dual-fuel systems}

Dual fuel supply systems in combustion engine were first invented in the United States in 1944, when Barnaby and Russell [4] patented a technical solution enabling stationary engines, usually operating on gas fuel, to also be supplied with an additional liquid fuel. The purpose of this solution was to supplement the temporary shortages of gaseous fuel in the combustion chamber, which could disrupt the continuity of engine operation.

The use of the dual-fuel supply system in diesel traction engines had its beginnings only a couple of years later, as it was tested already in 1946. Then, in the pages of the Popular Mechanics magazine [42], the concept by the SoconyVacuum Oil Company was presented, in which a carburetor system was used, mixing two different fuels fed from two separate tanks with air. The authors of the design employed this solution to use two types of gasoline with different octane numbers. They showed that the use of gasoline with an octane number of 70 for $95 \%$ of the test run was sufficient to prevent knocking, whereas the commonly used gasoline at that time was the more expensive type with an octane number of 80 . Even then, the economics of transport played a significant role in the development of these new technologies.

In addition to the cost-effectiveness of using different fuels simultaneously to power engines, other aspects were also analyzed, such as the environmental impact or increasing performance in different operating conditions.

One of the classic applications of a dual-fuel system is the simultaneous use of natural gas and diesel oil in compression-ignition $(\mathrm{CI})$ engines. The main energy carrier in this system is natural gas supplied by indirect injection, while a small dose of diesel fuel ensures compressionignition of the mixture can be reliably achieved.

Such modification of the classic compression ignition diesel engine brings with it a number of advantages. Methane (the main component of natural gas) is cheaper than diesel oil, that it partially replaces. In addition, its combustion, provided the right conditions, results in a smaller amount of carbon dioxide and nitrogen oxides being produced as well as an increase in the indicated pressure at full engine load [38]. Due to the different densities of the fuels used in this system, it is not possible to premix them, therefore they are supplied by separate systems.

There are many publications (including $[6,35,41]$ ) on premixing fuels before feeding them to the proper supply system. This method is suitable for fuels with a similar chemical composition and physical state. At the same time research mainly focuses on the influence of different proportions of fuels in the mixture on the increase of combustion efficiency [10, 13, 32], engine knock reduction [3, 28, 40] and the emission of harmful compounds in exhaust gases [1, 17, 24].

In Brazil [11] the FlexFuel system is widely used in passenger cars. It is possible to fill the vehicle's fuel tank with more than one type of fuel, most commonly unleaded gasoline along with ethanol. It is possible thanks to the constant adaptation of the engine control algorithm to the quality of the supplied fuel or fuel mixture.

$\mathrm{Xu}$ et al. [44] have proven that the addition of natural gas as a second fuel to power a diesel engine increases the engine's resistance to knock combustion, which may allow 
the use of a higher compression ratio. Moreover, an increase in indicated thermal efficiency was observed, as well as a reduction in $\mathrm{CO}$ and $\mathrm{HC}$ emissions at the expense of increased emissions of soot and nitrogen oxides.

Lata et al. [25] observed the dependence of the combustion parameters on the type of admixing gas fuel in the engine originally powered with diesel oil. A $30 \%$ share of LPG (liquified petroleum gas - a mixture of propane and butane) in the fuel mixture resulted in an increase in the rate of pressure rise by $1.37 \mathrm{bar} /{ }^{\circ} \mathrm{CA}$, the maximum pressure in the combustion chamber by 6.95 bar and the combustion time by $5^{\circ} \mathrm{CA}$. The same proportion of hydrogen in the fuel mixture resulted in an increase in these indicators by 0.82 bar $/{ }^{\circ} \mathrm{CA}, 8.44$ bar and $5^{\circ} \mathrm{CA}$, respectively. The mixture of three fuels: diesel oil, LPG and hydrogen resulted in an increase in the rate of pressure increase by $0.88 \mathrm{bar} /{ }^{\circ} \mathrm{CA}$. and maximum pressure by 5.25 bar, and a reduction of the combustion time by $4^{\circ} \mathrm{CA}$.

Yüksel et al. [46] added hydrogen to a gasoline engine in their research. It was found that the thermal losses to heating the coolant were decreased, while the losses due to exhaust gases did not change, compared to the use of only gasoline for engine supply.

Commonly known are dual indirect injection systems (PFI-PFI), but they are mainly used to deliver one fuel simultaneously (mainly motorcycle engines) or in a classic configuration of an engine powered by unleaded gasoline with a 4th generation LPG system [33].

A dual fuel injection system is defined in this paper as a system that supplies two different fuels via separate supply systems to the intake manifold or directly into the combustion chamber. The previously mentioned dual-fuel system: natural gas-diesel oil meets this criteria, because, due to the physicochemical properties of fuels, it is not possible to create a stable fuel mixture before delivering them to a controlled combustion process. To implement such a system, the PFI-DI system (port fuel injection-direct injection) is used. One fuel (natural gas) is delivered through the injection system to the intake manifold and the other (diesel) is delivered directly to the cylinder.

The PFI-DI system is also used for other fuel configurations, e.g. unleaded gasoline-LPG, as well as for an injection of a single fuel type from both systems.

\section{Effect of the excess air coefficient in the cylinder of a dual-fuel direct and indirect injection systems}

\subsection{Injection of diesel fuel and natural gas}

The use of two fuels in the form of diesel oil in combination with gaseous fuels is a subject of intensive research and wide industrial implementation. Diesel fuel is delivered directly and a part of its base dose is replaced by one of the gaseous fuels (LPG, CNG) supplied to the inlet duct.

Dose division is also analyzed when using dual fuel injection. Gilowski and Stelmasiak [14] proved that splitting the dose of diesel oil in a dual-fuel system (with natural gas) has a positive effect on increasing the efficiency of the engine for low and medium engine loads (by 1-3\%) and may improve the durability parameters of the engine by limiting of the rate of combustion pressure increase. How- ever, the cited research lacks the direction of further improvement possibilities of the combustion efficiency, hence it is impossible to clearly state about the potential of the used technology.

Research on creating a mixture in this way (natural gas - PFI, diesel fuel - DI) was carried out by, among others You et al. [45]. Various conditions of natural gas injection into the inlet channel were analyzed - Fig. 1a. It was found that increasing the gas injection advance, at different values of the excess air coefficient, first improves and then worsens the engine operating stability identified by CoV(IMEP) - Fig. 1b). The best conditions for the combustion process occur at gas injection angles in the crank angle range of $300-350^{\circ}$ before TDC, regardless of the excess air coefficient value. Increasing the share of fuel in the dose (reducing $\lambda$ value towards the stoichiometric mixture) leads to an improvement in the quality of the combustion process as indicated by the CoV (IMEP). The research points that during formation of multi-fuel mixture the optimal conditions of both fuels injection exist.

Another outcome of these studies was the conclusion that greater homogenization of the $\mathrm{CNG}$ and air mixture, achieved by placing the CNG injector further away from the intake valve, improves the combustion quality and lowers exhaust emissions. There is a growing trend towards analyzes related to the injection of two liquid fuels, with diesel oil being the main fuel.

a)

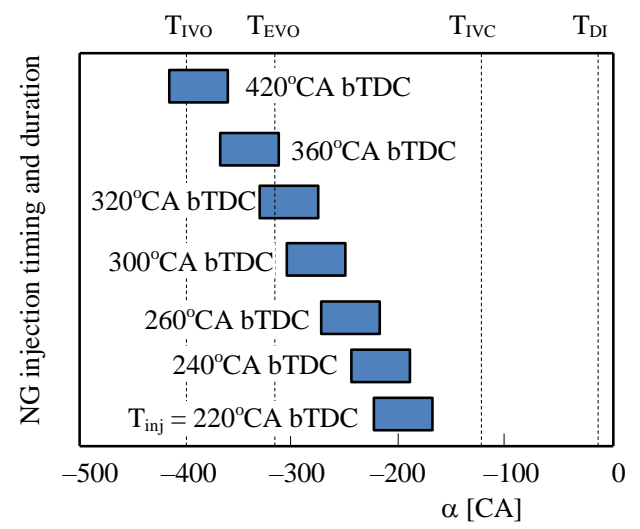

b)

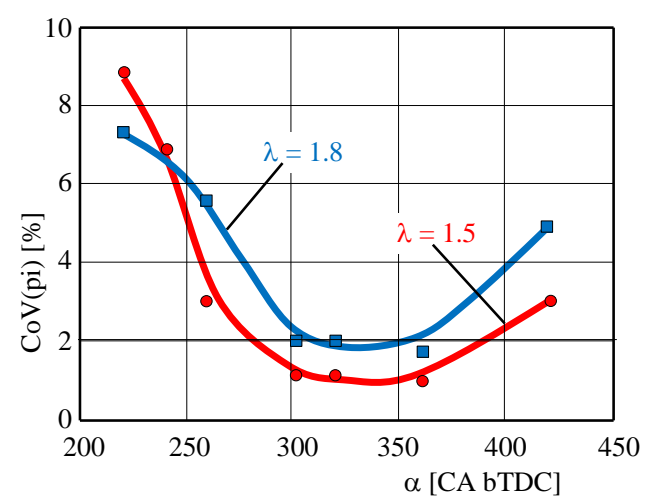

Fig. 1. Analysis of gas injection (a) and combustion process conditions (b): CNG injection into the inlet channel and DF injection into the cylinder at different values of the excess air coefficient [45] 


\subsection{Injection of diesel fuel and gasoline}

Research on this application was conducted by Lee et al. [26]. Using a single-cylinder $395 \mathrm{~cm}^{3}$ engine, they analyzed the combustion process when powered by direct diesel injection and indirect gasoline injection. The research used engine operation modes generating high indicated efficiency of about $45 \%$. This value was obtained by combining diesel fuel injection and a large mass fraction of gasoline (up to 70\%) Fig. 2. Injection of diesel fuel at the angle of $6^{\circ} \mathrm{CA}$ before TDC resulted in a typical heat release rate and was similar to the values observed when done with gasoline - Fig. 2a.

Increasing the DF injection advance angle results in a different heat release rate characteristic - Fig. $2 b$. This is due to injection of DF, which extends the mixing phase of the two fuels. This results in the appearance of the second peak of the heat release rate (at around $368^{\circ} \mathrm{CA}$ ) and a rapid increase in cumulative heat release.

Significant advance of the DF injection results in RCCI combustion - Fig. 2c. In relation to the DF injection itself, this causes the maximum cumulative heat release being reached before TDC, which leads to a faulty combustion process. In a dual-fuel system, the combustion center (CA50) is observed at around $8^{\circ} \mathrm{CA}$ after TDC. This is due to the significant advance of DF injection, amounting to about $50^{\circ} \mathrm{CA}$. However, there are visible areas of lowtemperature heat release - indicated as a slow increase in the observed heat release rate. The heat release rate is slowed down and at the same time it is the lowest among the three variants of DF injection. The tests were carried out for three values of the excess air coefficient: $\lambda=1.72,2.72$ and 2.77. The maps showing the three engine operation modes described above were shown in Fig. 3.

Applying two basic fuels simultaneously clearly shows the potential of increasing the combustion efficiency. Combining this solution with RCCI system requires further research on elaborating the implementation potential in transportation sector.

\subsection{Injection of gasoline with other fuels}

The research on dual-fuel systems where the base fuel is gasoline and supplied additionally with alcohols has been analyzed quite thoroughly in the literature. Especially in terms of the excess air coefficient being $\lambda=1$. Kalwar et al. [22] is an example of such studies. However, in this case, it is not possible to analyze changes in the excess air coefficient and make it dependent on the conditions and amount of individual fuels injected.

In SI engines, the topic currently being explored is the use of LPG in combination with gasoline injection or its

a)

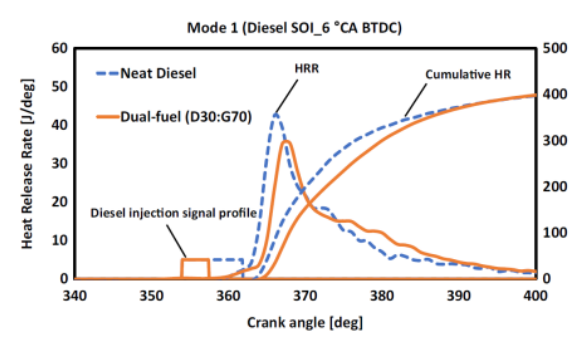

b)

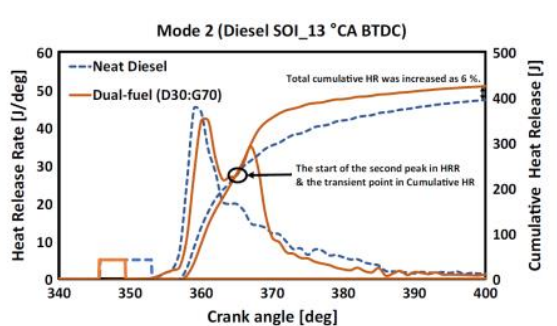

complete replacement in the engine supply [36]. Mitukiewicz et al. [31] carried out research on creating a mixture of LPG with air (via indirect injection) and using it to replace gasoline supplied to the engine (via direct injection). When determining the dose of LPG fuel to be supplied, the authors made an assumption that the engine would operate at the same global excess air coefficient as for gasoline alone.

Research on the possibilities of creating a stratified mixture with the use of LPG was carried out by Boretti and Watson [8]. The authors found that combustion of the stratified mixture with the use of direct LPG injection is possible and leads to a reduction in fuel consumption at full engine load, with a global excess air coefficient of $\lambda=1.65$. However, they assume that enabling the LPG engine to work for lean mixtures under all load conditions would be possible with the use of turbulent ignition and a prechamber. The formation of a mixture in such a chamber is distinct from the formation of a stratified mixture in the combustion chamber as the aim is to create a homogeneous mixture in a smaller volume.

The popularity of applying LPG results from the low price of this fuel and the possibility of relatively easy adoption of the original single fuel supply system.

Research conducted by Ji et al. [20] concerned petrol and hydrogen fuel supply systems with indirect injection of both fuels. Combustion was carried out until the content of hydrogen reached $6 \%$. It was found that the engine's thermal efficiency increased significantly from 26\% (using gasoline) to over $31 \%$ with the addition of $6 \%$ hydrogen. At the same time, the use of lean mixtures was increased from 1.5 (petrol) to over 1.65 (petrol + hydrogen $\rightarrow 6 \%$ ) - Fig. $4 \mathrm{a})$. The use of hydrogen, despite making the fuel mixture more lean, improves the stability of the combustion process. It has been shown that in the entire range of hydrogen combustion at $6 \%$ of content the CoV(IMEP) does not exceed $1 \%$ - Fig. 4b. Despite the fact that the research direction on the enriching the mixture with hydrogen seems promising, the authors did not take into account the changes adopting the ignition point to the lambda value of the mixture. It can lead to the illusory observation of the loss of combustion stability of lean mixture without hydrogen.

An analysis of gasoline and hydrogen injection using the indirect and direct injection technique was carried out by Sun et al. [39]. Two variants of fuel injection were used in that research: indirect and direct injection with gasoline $(\mathrm{PFI}+\mathrm{GDI})$, and indirect injection with gasoline with direct injection of hydrogen $(\mathrm{PFI}+\mathrm{HDI} \rightarrow$ hydrogen direct injection). In both cases, the observed value of the excess

Fig. 2. Combustion process conditions for single-fuel and dual-fuel (DF and gasoline) for an engine with different fuel supply modes: a) mode 1, b) mode 2, c) mode 3 (reproduced from [26]) 

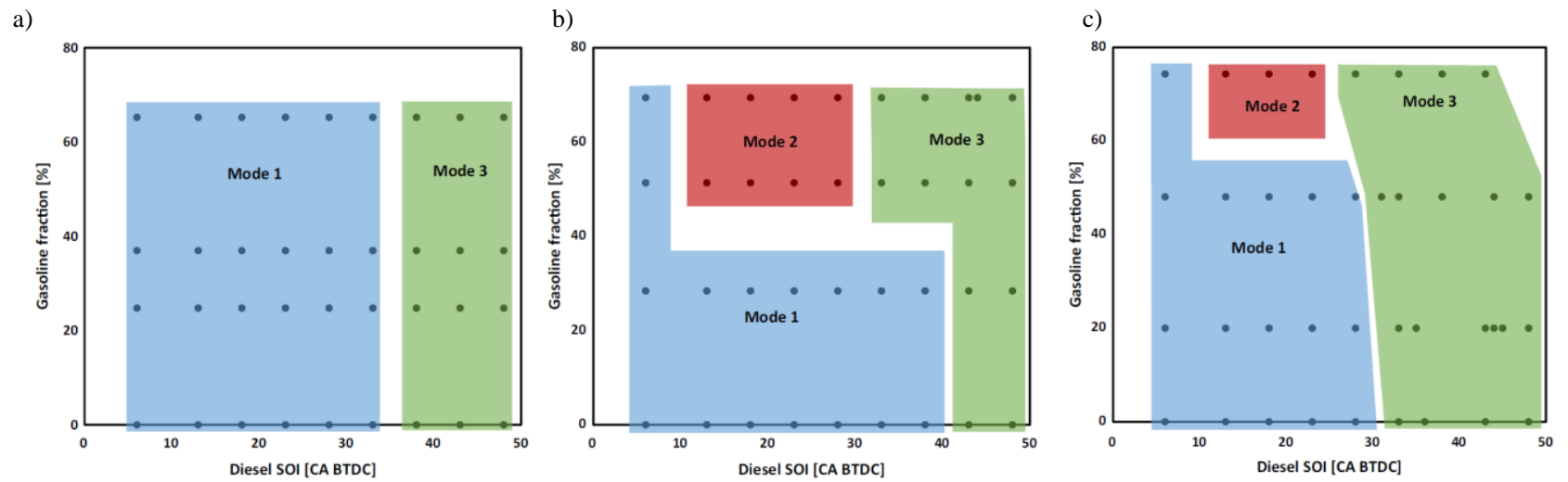

Fig. 3. Dual-fuel engine operating points maps: diesel and gasoline at different values of the excess air coefficient: a) $\lambda=1.72$, b) $\lambda=2.72$, c) $\lambda=2.77$ (reproduced from [26])

a)

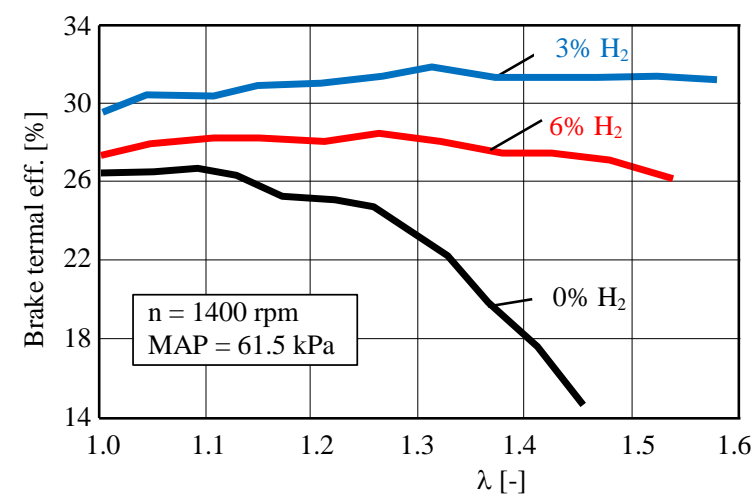

b)

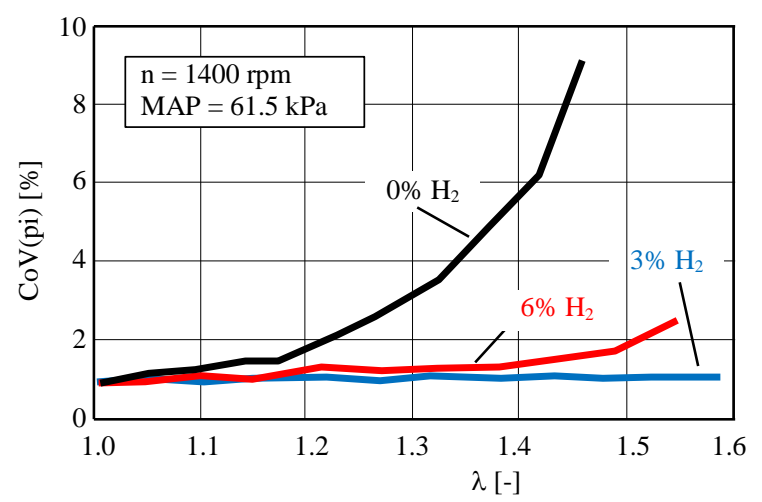

Fig. 4. Change of dual-fuel engine operating indicators: a) thermal efficiency, b) engine combustion instability coefficient [20]

air coefficient was the resultant value of $\lambda=1$. It was found that the increase in the share of direct gasoline injection in the PFI + GDI system led to a slight decrease in the engine power output (by about $2 \%$ ). However, when using the PFI + HDI system (with direct hydrogen injection), an increase in power of up to $5 \%$ was found in the same scenario. This is mainly due to the need to allow the fuel dose time to mix (gasoline fed in the compression stroke), where reducing

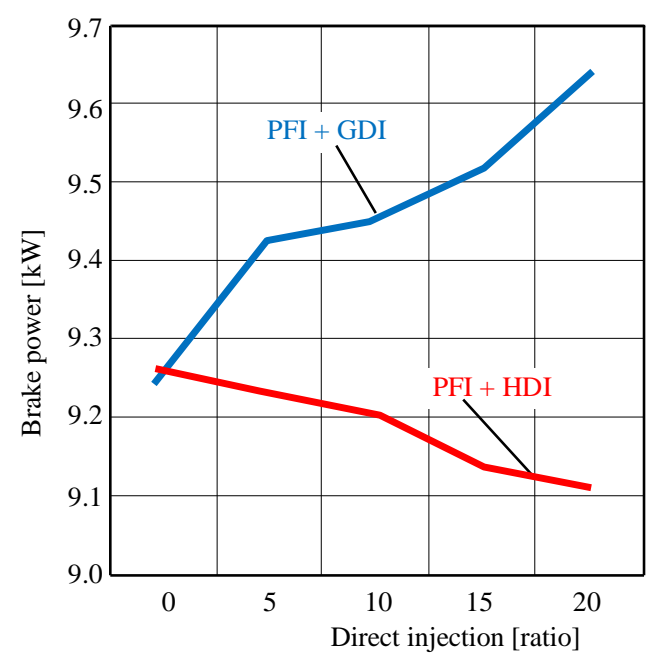

Fig. 5. The change in engine power output as a result of different dual fuel engine supply methods [39] that time leads to a deterioration of the combustion process - Fig. 5.

Slightly different studies were published by Huang et al. [19]. They performed ethanol direct injection (EDI) and gasoline port injection (GPI). By comparing direct gasoline injection and EDI + GPI injection methods, the distribution of the excess air coefficient was analyzed (Fig. 6).

Knowing that the ignitability of the fuel dose in the vicinity of the spark plug is a critical factor, and the value of the excess air coefficient was $2<\lambda<0.66$ [27], analyzes of the spark plug cross-section were performed.

It was found that during the combustion of just gasoline injected into the intake duct (GPI), the value of the excess air coefficient in the vicinity of the spark plug was $\lambda=1.15$.

In the case of EDI + GPI injection, this value was $\lambda=$ $=1.66$. Both are within the above-mentioned critical flammability range of the fuel dose in a SI engine.

Similar studies were conducted by Guo et al. [16] using a mixture of acetone, butanol and ethanol as fuel, and with the second fuel being gasoline. Direct and indirect injection methods were also used. The following variants were analyzed: a) ADI + GPI - acetone and others as direct injection (ADI - acetone direct injection) and indirect petrol injection (GPI), b) API + GDI (gasoline direct injection) and c) GDI + GDI.

The research was carried at $50 \%$ share for each fuel (energy differences were up to $0.56 \%$ ). It was found that for each of the mixtures it is possible to carry out the combus- 
tion process in the lambda range of $\lambda=0.9-1.3$. The most critical is burning lean mixtures; the lowest $\mathrm{CoV}$ (IMEP) values were found in the GPI + ADI configuration, reaching below $1.3 \%$. Also in this fuel supply configuration, the highest values of torque and the highest value of thermal efficiency were obtained. This configuration was also the best in terms of the number and mass of solid particles emitted (especially when burning lean mixtures for $\lambda=$ $=1.3)$.

a)

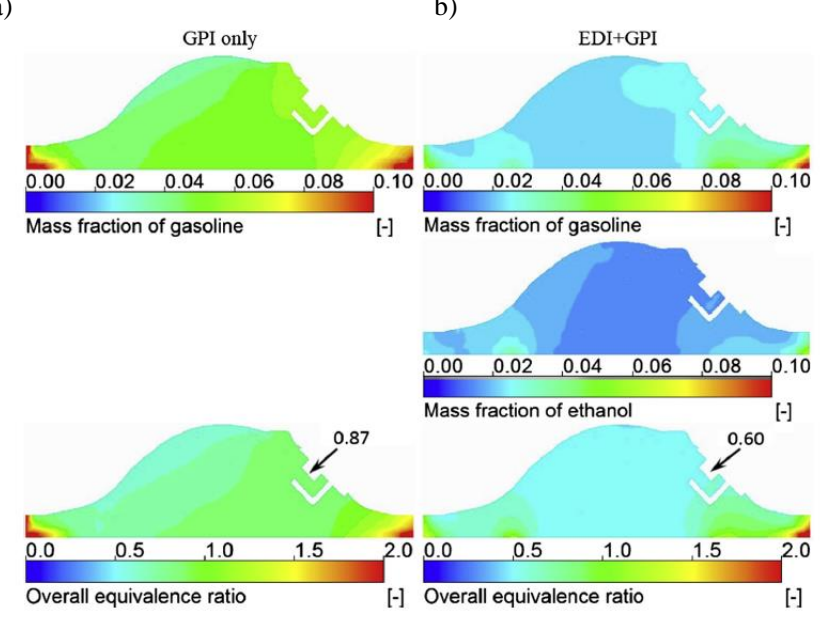

Fig. 6. Distribution of gasoline and ethanol mass (a) in the combustion chamber, and the excess air coefficient (b) when supplying the engine with gasoline (GPI) and ethanol with gasoline (EDI + GPI) (reproduced from [19])

\subsection{Injection of methanol with other fuels}

The research on dual fuel supply, in which the primary fuel was methanol (direct injection) with the addition of hydrogen (PFI) was conducted by Gong et al. [15]. Knowing the general properties of hydrogen related to increasing the combustion rate, especially in combination with lean mixtures, it was used as an additive in a small quantity (3$6 \%$ ). A strategy of delayed injection of methanol into the cylinder was used. It was found that the addition of hydrogen (in the 3-6\% range) extends the possibilities of burning lean mixtures from $\lambda=1.6$ when burning pure methanol to $\lambda=2.2$. The necessity to adjust the ignition angle depending on the excess air coefficient was also confirmed. With a $6 \%$ addition of hydrogen and at $\lambda>2$ the $\operatorname{CoV}$ (IMEP) value was found to be below $3.5 \%$.

\section{Effect of the cylinder excess air coefficient in a dual fuel DI system}

\subsection{Injection of gasoline with other fuels}

Previous solutions of gasoline and ethanol injection concern mainly mixtures of E85 (ethanol - 85\% and gasoline $-15 \%$ ) and E15 (gasoline $-85 \%$ and ethanol - 15\%) [4]. The research of dual-fuel direct injection systems of gasoline and ethanol was conducted by Kang et al. [23]. The analyzes include supply with a stoichiometric mixture. Despite this, it was possible to vary the size of the doses of individual fuels in order to obtain the stoichiometric mixture as needed (Table 1).

The fuel doses presented in the table were used in experimental studies. Increasing the proportion of ethanol makes it possible to increase the start of ignition angle. This leads to an increase in combustion pressure and an increase in BMEP (Fig. 7).

Studies have also shown that increasing the proportion of ethanol reduces the $\mathrm{CoV}$ (IMEP). In the absence of ethanol, this ratio was approximately $4 \%$. Increasing the proportion of ethanol to $10 \%$ resulted in a $50 \%$ reduction in $\mathrm{CoV}(\mathrm{IMEP})$ value. A further increase in the share of ethanol lead to this indicator reaching the value of $1-1.5 \%$ (with the permissible limit value being $1.5 \%$ ).

Table 1. Energy shares of fuels in gasoline-ethanol blends [23]

\begin{tabular}{|c|c|c|c|}
\hline $\begin{array}{c}\text { Ethanol } \\
\text { share }\end{array}$ & $\begin{array}{c}\text { Energy content } \\
\text { in gasoline }\end{array}$ & $\begin{array}{c}\text { Energy content } \\
\text { in ethanol }\end{array}$ & $\begin{array}{c}\text { Total energy } \\
\text { in the fuel }\end{array}$ \\
\hline$[\%]$ & {$[\mathrm{MJ}]$} & {$[\mathrm{MJ}]$} & {$[\mathrm{MJ}]$} \\
\hline 0 & 75.80 & 0 & 75.80 \\
\hline 10 & 67.86 & 8.13 & 75.99 \\
\hline 25 & 56.59 & 19.69 & 76.25 \\
\hline 50 & 34.26 & 42.51 & 76.78 \\
\hline 75 & 19.01 & 58.12 & 77.13 \\
\hline 100 & 0 & 77.58 & 77.58 \\
\hline
\end{tabular}

a)

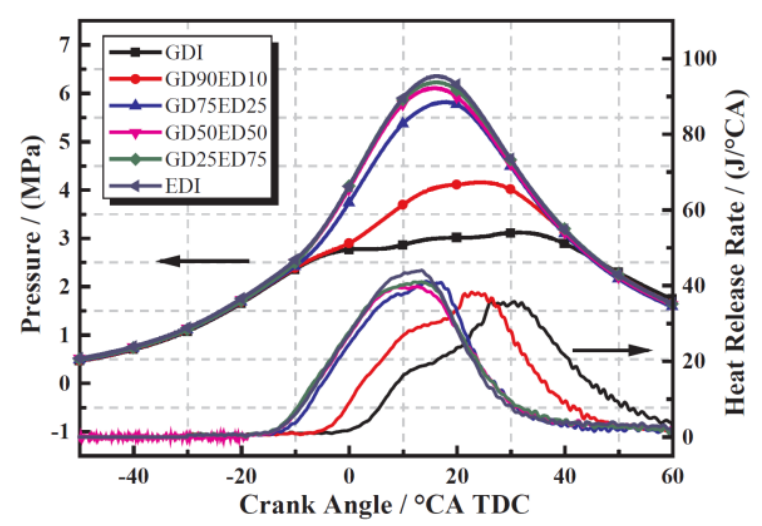

b)

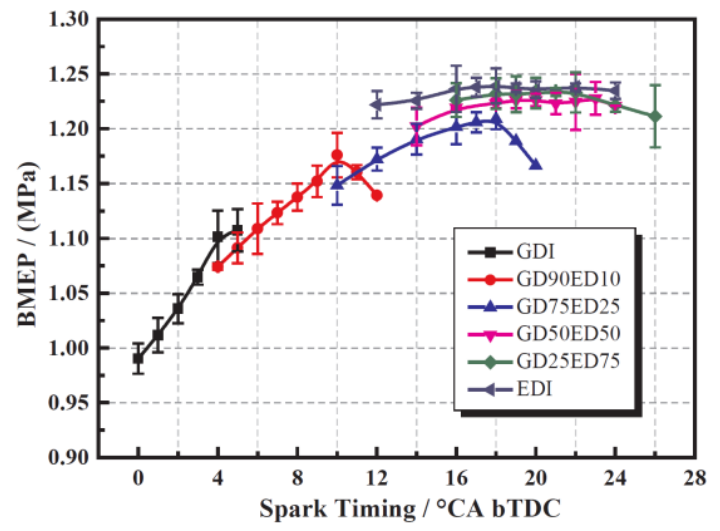

Fig. 7. Indicator tests: a) cylinder pressure curve, b) changes in BMEP as a function of the start of ignition angle (reproduced from [23])

The injection strategy of gasoline direct injection plus ethanol direct injection mode can further expand engine load range compared with the conventional direct injection. The reason is that the fuel latent heat of vaporization is more efficiently used to reduce fuel dose air temperature and increase the volumetric efficiency when both gasoline and ethanol are injected directly into cylinder. 
Gasoline direct injection plus ethanol direct injection mode can increase the mean effective pressure and thermal efficiency simultaneously.

The authors of the following article conducted the research on the novel method of mixture forming using two different hydrocarbon fuels. The original dual direct injection tests relied on the injection of gasoline and other fuels (ethanol, n-butanol and n-heptane). The tests were carried out with the use of a rapid compression machine (Fig. 8).

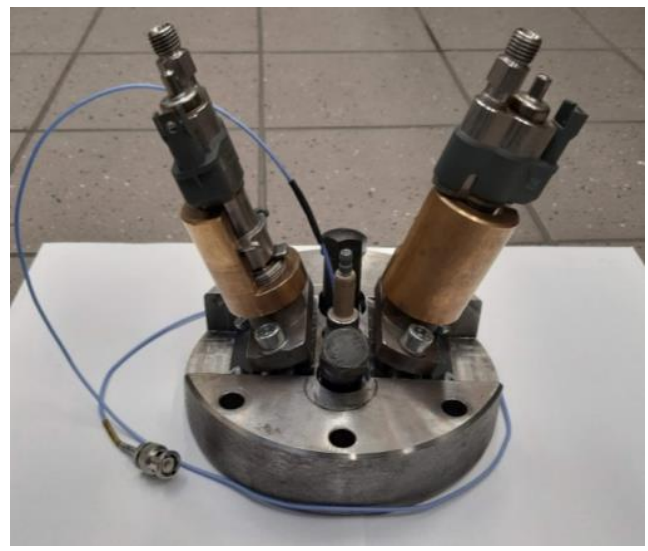

Fig. 8. The RCM head adjusted for the dual-fuel injection system

Fuel was supplied by two high-pressure injection pumps from the BMW M4 GTS. The original system was modified by disconnecting the cable connecting the two pumps, which made it possible to supply the system with two different fuels independently (Fig. 9). The system enables independent fuel pressure adjustment in the range of 5-30 MPa.

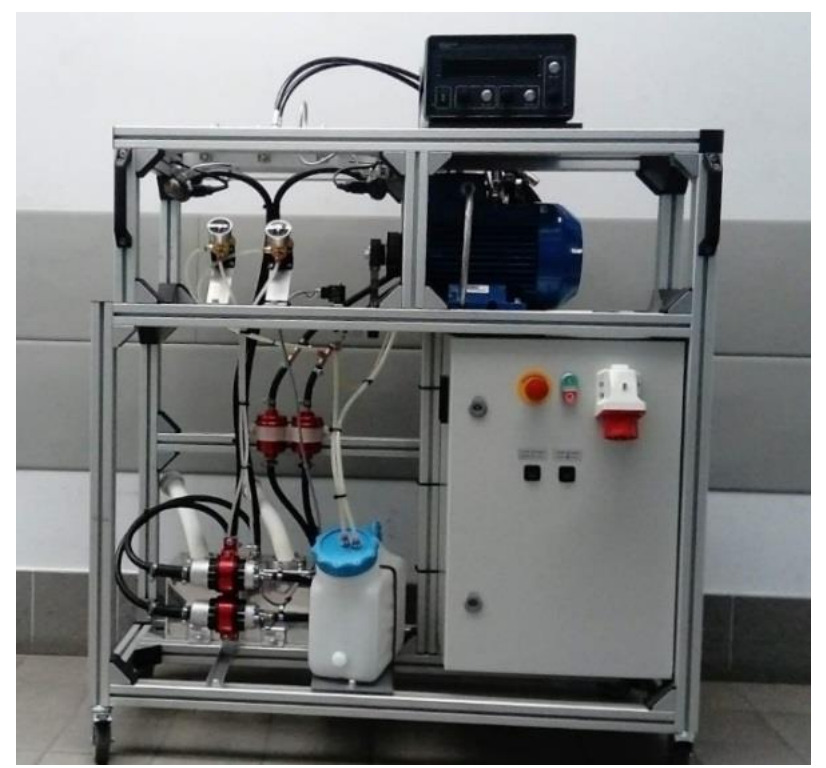

Fig. 9. High pressure pump stand with a fuel pressure regulation system

The tests were carried out in the form of injecting the same fuel (Fig. 10a) and different fuels with the two injectors (Fig. 10b).

The observed heat release loss results from the specificity of operation of such a system and the heat escape. The symmetrical piston movement causes the phenomenon, that the heat release rate is always positive [e.g. 37]. However, the application of a slider system, in which the typical cranking system does not exist, causes the different heat release rate course - it is in a certain portion of combustion - negative. The negative values of $d Q$ lead to the heat release loss. Such results can be obtained in research using an RCEM without typical cranking system [e.g. 21, 43].

Based on the conducted research, it was found that among the analyzed fuel configurations, the gasoline + n-butanol fuel supply configuration was the most efficient; the efficiency value for this test case was $27.8 \%$ and was higher by $6.1 \%$ than for the base configuration, i.e. with the use of gasoline only.

a)

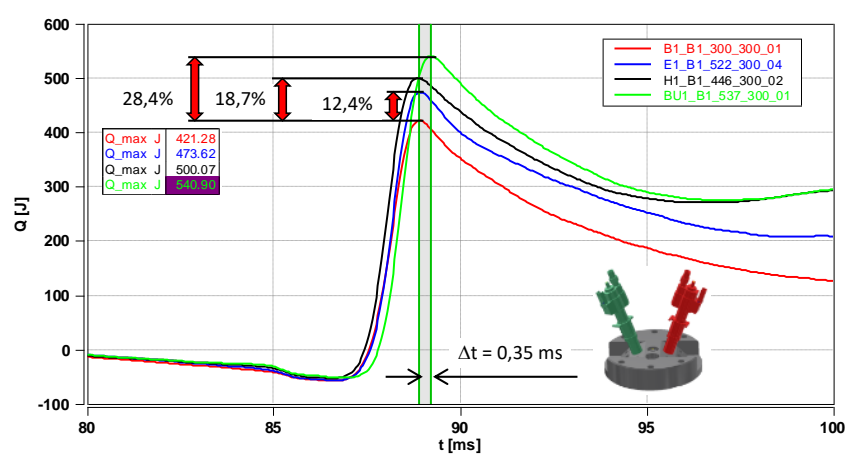

b)

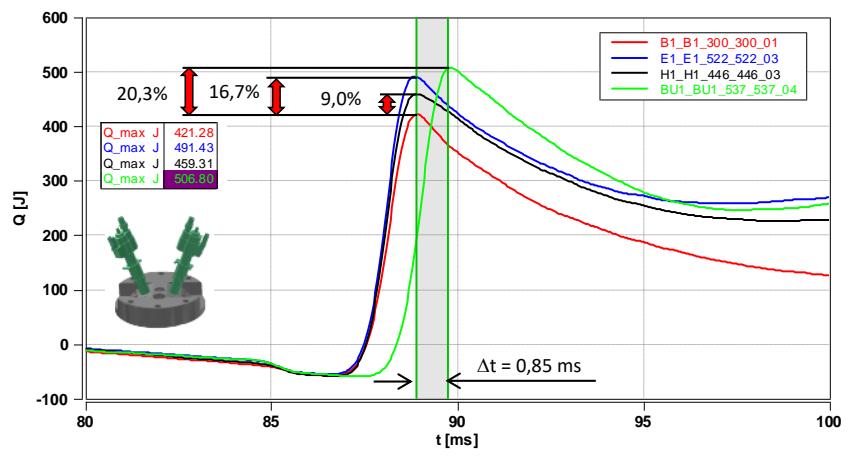

Fig. 10. Effect of fuel type on heat release: a) injection of the same fuel, b) injection of different fuels

The combustion of gasoline and n-butanol mixture in relation to the combustion of gasoline alone resulted in:

- maximum combustion pressure in the cylinder being $10 \%$ higher; changes observed for other fuel mixtures reached values up to $4 \%$,

- the pressure increase being $17 \%$ greater; combustion of the other analyzed mixtures indicates changes in this value of up to $7 \%$ in comparison,

- maximum heat release rate being $22 \%$ greater; where other fuel mixtures generated smaller differences of up to $8 \%$ at most,

- the maximum amount of total heat released being $22 \%$ higher; changes of this indicator for other fuel mixtures compared to gasoline were: $13 \%$ (for petrol and ethanol) and $8 \%$ (for petrol and $\mathrm{n}$-heptane). 


\subsection{Injection of diesel fuel with other fuels}

Simulation tests with the use of DF and LPG fuels were conducted by Boretti [7]. The validation was used only for diesel injection in the engine. The other studies in the dualfuel system were not validated. Simulation analyzes were performed with the use of the WAVE software, obtaining maps defining the shares of DF and LPG fuels.

Therefore, it was possible to create maps of the excess air coefficient values, which were shown in Fig. 11. It shows that with increasing engine load, the share of LPG fuel increases and the share of diesel fuel decreases. At the same time, the excess air coefficient decreases, and in the conditions of the full power characteristics it takes values in the range $\lambda=1.1-1.2$.

Despite considerable design difficulties, Long et al. [30] used a dual-direct injection system in a compression ignition engine. This solution uses a premixed charge system prepared by the main pre-injection blended fuels of diesel

a)

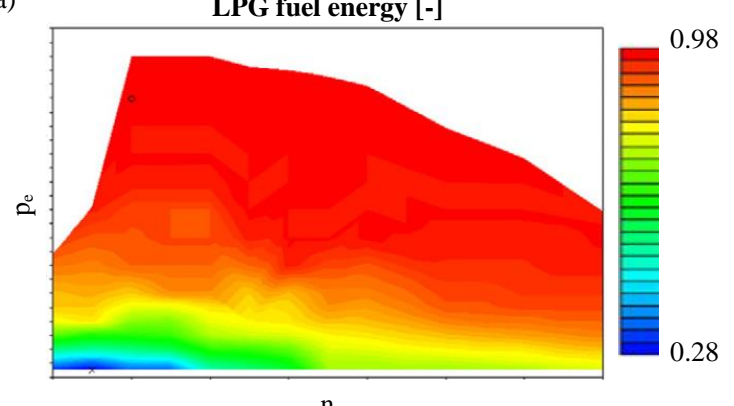

c)

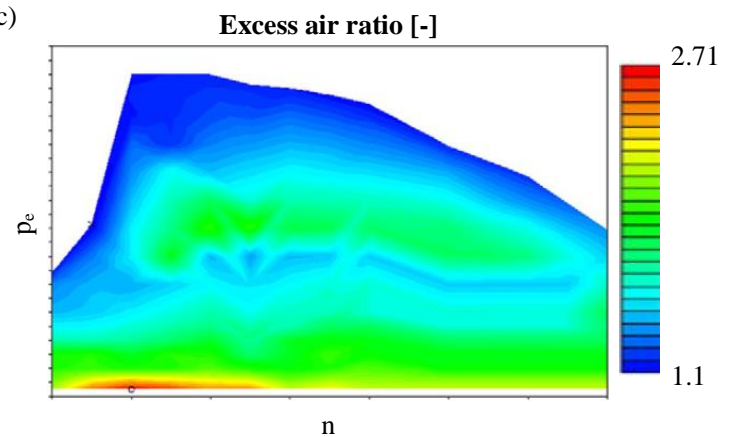

and ethanol-gasoline. The system called Jet Controlled Compression Ignition (JCCI) was shown in Fig. 12. The tests were carried out with a single-cylinder engine with a cylinder diameter of $86 \mathrm{~mm}$ and a compression ratio of 15.5. The typical compression chamber of the diesel engine has been replaced with a flat chamber to fit the premixed combustion mode. The fuel used was a mixture of gasoline and ethanol with diesel fuel constituting $15 \%$ (D15) or $30 \%$ (D30) fuel share by mass. The injection system was equipped with two fuel injection pumps operated independently. The fuel injection pressure in the pre and maininjection systems was maintained at $60 \mathrm{MPa}$ (in the case where the engine load was over $50 \%$, the fuel injection pressure was increased to a maximum of $90 \mathrm{MPa}$ ). Diesel oil was supplied by the central injector (fuel injection direction being in line with the piston movement). The injector placed at angle supplied the mixture of D15 or D30 at an angle of 10 degrees - Fig. 13.

b)

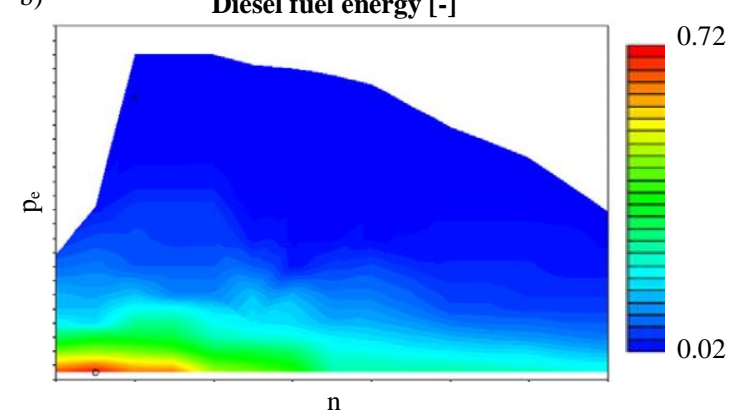

d)

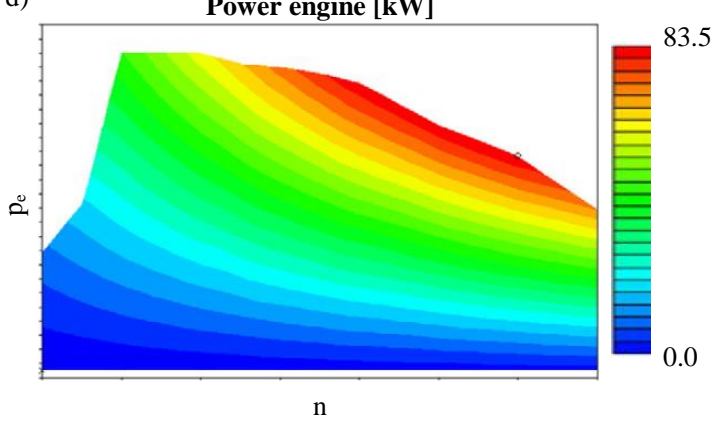

Fig. 11. Simulation analysis of the excess air coefficient overlayed on the general characteristics of an engine using a combined DF and LPG injection: a) LPG energy share, b) Diesel fuel energy share, c) excess air coefficient, d) engine power (reproduced from [7])

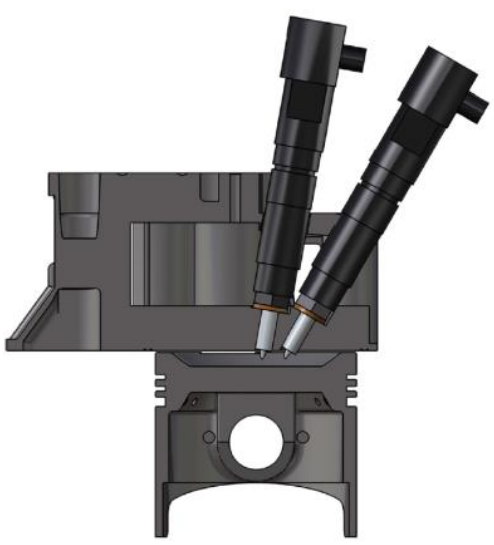

Fig. 12. Diagram of the JCCI combustion system design (reproduced from [30])
The experimental results and analysis demonstrated that the fuel JCCI mode with dual-direct injection strategy could effectively and robustly control the combustion event and emissions of premixed combustion mode.

Dual-fuel direct fuel injection systems currently apply apart from the examples presented above - also to the injection of methanol and DF [12] as well as to n-butanol in combination with biodiesel [47]. The comprehensive review of different variants of powering systems and fuels has been put together by Saiteja and Ashok in [2]. In the paper by Ning et al. [34] from 2020, 10 additional publications on direct injection of two different fuels were cited, for DF and methanol mix. Simulation studies using diesel oil and n-butanol fuel were conducted by Cai et al. [9]. Various combustion systems were implemented with the simulation apparatus: 
HCCI: n-butanol (PFI)

PCCI: n-butanol in-cylinder early single injection

RCCI: n-butanol (PFI) + diesel (DI)

$\mathrm{DI}^{2}$ : n-butanol (DI) + diesel DI.

An example comparison of pressure curves in a cylinder was shown in Fig. 14.

a)

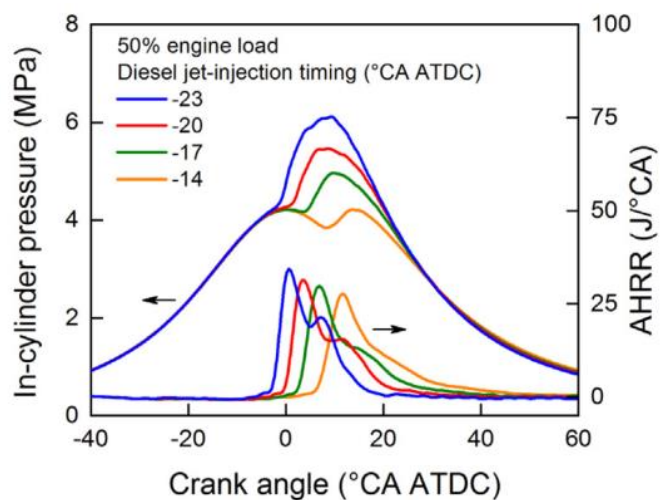

b)

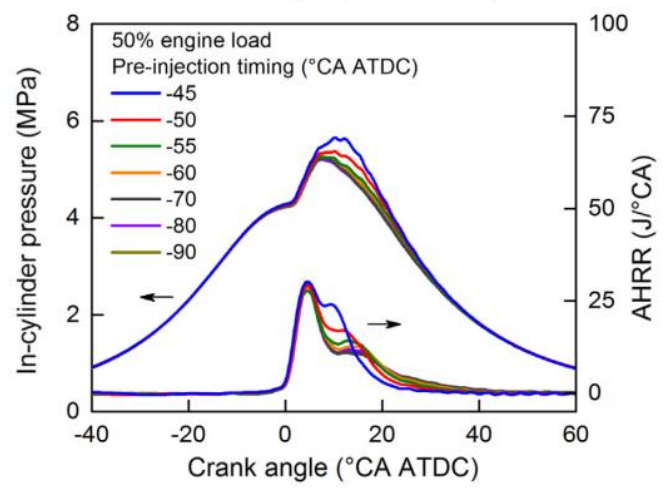

Fig. 13. Changes in cylinder pressure and heat release rate: a) during main injection, b) during pre-mixed combustion (reproduced from [30])
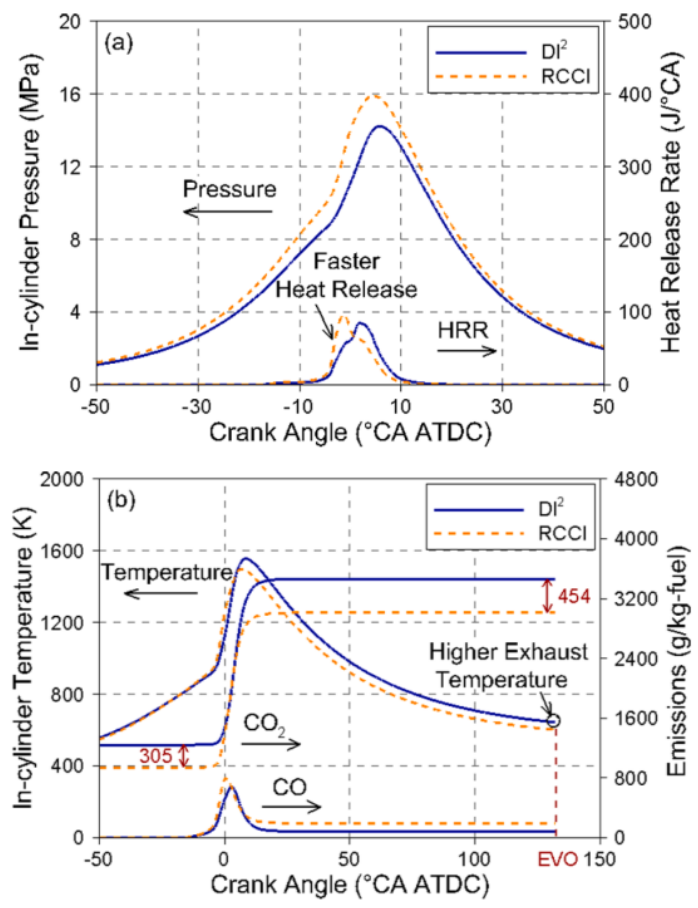

Fig. 14. In-cylinder pressure, heat release rate, temperature, $\mathrm{CO}$, and $\mathrm{CO}_{2}$ emission characteristics for representative cases of $\mathrm{DI}^{2}$ and RCCI (reproduced from [9)]
The reason for the differences in incomplete combustion between the two strategies is primarily related to the different fuel delivery strategies. In RCCI, part of the premixed n-butanol distributes itself within the low temperature squish region near the liner, which cannot be completely oxidized due to its too low local equivalence ratio. By contrast, n-butanol and diesel with different injection timings and spray angles are directly injected into the cylinder in $\mathrm{DI}^{2}$ by two separate nozzles, hence the in-cylinder distribution of the fuel/air mixture can be effectively modulated. As indicated in Fig. 15 for $\mathrm{DI}^{2}$, the fuel within the squish region can also be well oxidized.
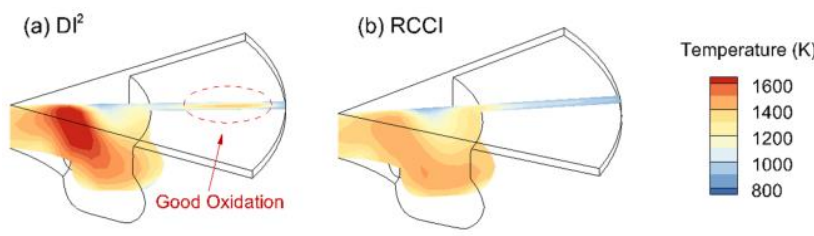

Fig. 15. Comparison of the in-cylinder temperature distribution between the representative cases of $\mathrm{DI}^{2}$ and RCCI at CA50 (reproduced from [9])

In studies conducted by Dong et al. [12] analyzes of the injection of methanol (injected centrally in the cylinder) and diesel fuel (non-axial injection) were performed. Changes in the excess air coefficient were not analyzed. The research was conducted in the aspect of replacing diesel fuel with methanol in the range of $45 \%$ to $95 \%$. The research results were summed up in Fig. 16.

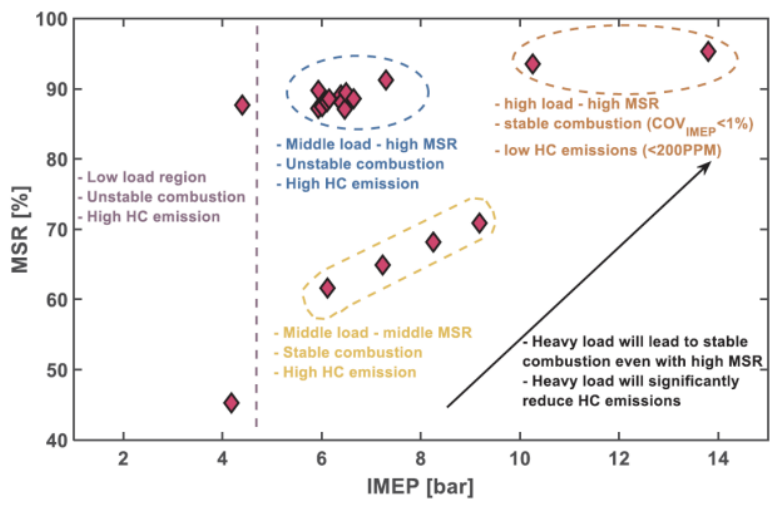

Fig. 16. Summary of studies on direct injection of $\mathrm{MeOH}$ and DF (reproduced from [12])

Similar studies were also conducted by Huang et al. [18]. Direct injection of two fuels was used; those being methanol and biodiesel. The tests were carried out in the ICCI (Intelligent Charge Compression Ignition) system. This combustion mode was proposed to realize flexible stratifications of concentration and reactivity with the best gradient in accordance with the engine operating conditions. In ICCI mode, most of low-reactivity fuel is directly injected during the intake stroke with a single or multiple stage split injection. Then, the rest of low-reactivity fuel and high-reactivity fuel are directly injected in succession to establish crossed stratifications of the equivalence ratio and reactivity in the cylinder.

The analysis of the combustion pressure change with the use of methanol and biodiesel was shown in Fig. 17. 


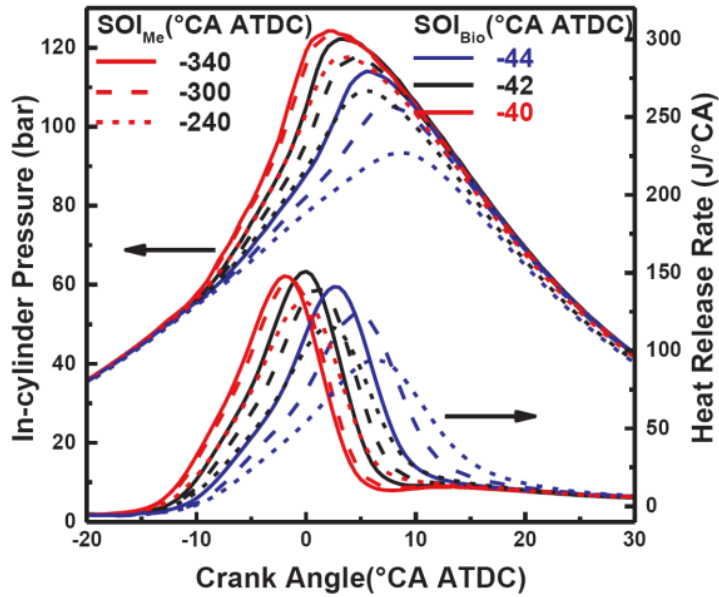

Fig. 17. Effects of fuels injection timings on the in-cylinder pressure and heat release rate (methanol energy ratios $=30 \%$ ) (reproduced from [18])

Fueling the internal combustion engine with hydrogen and diesel fuel in the hydrogen-diesel dual direct injection (H2DDI) system was presented by Liu et al. [29]. Hydrogen was injected into the cylinder at a pressure of $20 \mathrm{MPa}$. The tests were carried out on a single-cylinder engine (adapted from a four-cylinder engine) with a modified compression ratio to 17.4 .

The results of supplying the engine with hydrogen and diesel oil were shown in Fig. 18.

As a result of the conducted research, it was found that:

- Direct injection of hydrogen into the cylinder results in up to $10 \%$ increase in the end-of-compression pressure, which is associated with additional compression work. At later injection timings, this effect is less pronounced.

- Under the conditions of this work, the shape of the apparent heat release rate (aHRR) resembles that of the baseline diesel combustion, except when hydrogen is injected late resulting in insufficient mixing time, in which case slower aHRR indicative of a hydrogen mixing controlled combustion is observed.

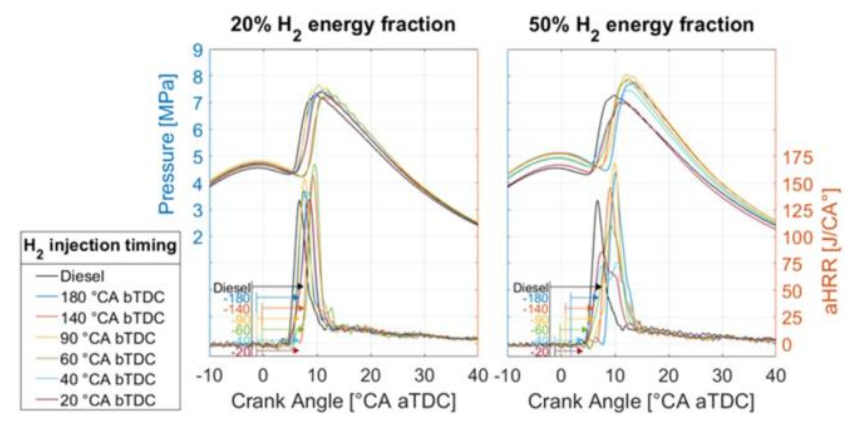

Fig. 18. Effect of hydrogen injection timing on in-cylinder pressure and apparent heat release rate (aHRR) at selected hydrogen energy fractions of $20 \%$ (left) and 50\% (right) (reproduced from [29])

\section{Conclusions}

Direct dual-fuel injection has already been implemented with various fuels. These systems can be classified according to the dominant fuel:

- gasoline with/without other fuels,

- diesel fuel with/without other fuels,

- hydrogen with/without other fuels.

The variety of these solutions in connection with the possibility of also using indirect injection causes the implementation of combustion systems to be:

- homogeneous (HCCI): PFI,

- stratified (PCCI): PFI + DI,

- reactivity stratification combustion $(\mathrm{RCCI})$ : PFI + DI.

The search for new combustion systems contributes to increasing the internal combustion engines efficiency, the possibility of achieving better combustion process control (including controlling the excess air coefficient in the cylinder), as well as intensifying development works in the field of alternative fuels (butanol, methanol, hydrogen) as well as synthetic fuels.

\section{Nomenclature}

ADI acetone direct injection

CI compression ignition

CNG compressed natural gas

$\mathrm{CoV}$ coefficient of variation

D30 diesel (30\%)

DI direct injection

$\mathrm{DI}^{2}$ dual direct injection

EDI ethanol direct injection

G70 gasoline (70\%)

GDI gasoline direct injection

GPI gasoline port injection

H2DDI hydrogen-diesel dual direct injection

IMEP indicating mean effective pressure
JCCI jet controlled compression ignition

LPG liquified petroleum gas

MAP manifold air pressure

$\mathrm{MeOH}$ methanol

MFB mass fuel burn

NG natural gas

PFI port fuel injection

RCCI reactivity controlled compression ignition

SI spark ignition

SOI start of injection

TDC top dead centre

$\lambda$ excess air ratio

\section{Bibliography}

[1] ALASFOUR, F.N. $\mathrm{NO}_{\mathrm{x}}$ emission from a spark ignition engine using 30\% iso-butanol - gasoline blend: part 2 - ignition timing. Applied Thermal Engineering. 1998, 18(8), 609-618. https://doi.org/10.1016/s1359-4311(97)00082-3
[2] ASHOK, B., ASHOK, S.D., KUMAR, C.R. LPG diesel dual fuel engine - a critical review. Alexandria Engineering Journal. 2015, 54(2), 105-126.

https://doi.org/10.1016/j.aej.2015.03.002 
[3] BARAL, B., RAINE, R. Knock in a spark ignition engine fuelled with gasoline-kerosene blends. SAE Technical Paper 2008-01-2417. 2008. https://doi.org/10.4271/2008-01-2417

[4] BARNABY, J., RUSSELL, W. Dual fuel engine. Patent US2400219A, 15.12.1944.

[5] BENAJES, J., GARCÍA, A., MONSALVE-SERRANO, J. et al. Benefits of E85 versus gasoline as low reactivity fuel for an automotive diesel engine operating in reactivity controlled compression ignition combustion mode. Energy Conversion and Management. 2018, 159, 85-95.

https://doi.org/10.1016/j.enconman.2018.01.015

[6] BOGIN, G.E., LUECKE, J., RATCLIFF, M.A. et al. Effects of iso-octane/ethanol blend ratios on the observance of negative temperature coefficient behavior within the Ignition Quality Tester. Fuel. 2016, 186, 82-90.

https://doi.org/10.1016/j.fuel.2016.08.021

[7] BORETTI, A. Numerical study of the substitutional diesel fuel energy in a dual fuel diesel-LPG engine with two direct injectors per cylinder. Fuel Processing Technology. 2017, 161, 41-51. https://doi.org/10.1016/j.fuproc.2017.03.001

[8] BORETTI, A., WATSON, H. Development of a direct injection high efficiency liquid phase LPG spark ignition engine. SAE International Journal of Engines. 2009, 2(1), 1639-1649. https://doi.org/10.4271/2009-01-1881

[9] CAI, Y., JIA, M., XU, G. et al. Feasibility study of the combustion strategy of n-butanol/diesel dual direct injection (DI2) in a compression-ignition engine. Fuel. 2021, 289, 119865. https://doi.org/10.1016/j.fuel.2020.119865

[10] DALHA, I.B., SAID, M.A., KARIM, A. et al. Reactivity controlled compression ignition: an advanced combustion mode for improved energy efficiency. In: Sulaiman S. (eds) Energy efficiency in mobility systems. Springer, Singapore 2020. https://doi.org/10.1007/978-981-15-0102-9_6

[11] DE FERREIRA GOMES, P., MENDES, C., LOPES, G. et al. High efficiency flex-fuel engines and the end of the $70 \%$ paradigm. SAE Technical Paper 2017-36-0162. 2017.

https://doi.org/10.4271/2017-36-0162

[12] DONG, Y., KAARIO, O., HASSAN, G. et al. High-pressure direct injection of methanol and pilot diesel: A non-premixed dual-fuel engine concept. Fuel. 2020, 277, 117932. https://doi.org/10.1016/j.fuel.2020.117932

[13] ELFASAKHANY, A. Gasoline engine fueled with bioethanol-bio-acetone-gasoline blends: Performance and emissions exploration. Fuel. 2020, 274, 117825. https://doi.org/10.1016/j.fuel.2020.117825

[14] GILOWSKI, T., STELMASIAK, Z. Impact of symmetrical division of initial dosage diesel oil on the selected thermodynamic parameters of the working medium and operation parameters dual fuel engine fuelled CNG. Combustion Engines. 2013, 154(3).

[15] GONG, G., LI, Z., YI, L. et al. Experimental investigation of equivalence ratio effects on combustion and emissions characteristics of an $\mathrm{H}_{2} /$ methanol dual-injection engine under different spark timings. Fuel. 2020, 262, 116463. https://doi.org/10.1016/j.fuel.2019.116463

[16] GUO, Z., YU, X., LI, G. et al. Comparative study of different injection modes on combustion and particle emission of acetone-butanol-ethanol (ABE) and gasoline in a dual-injection SI engine. Fuel. 2020, 281, 118786. https://doi.org/10.1016/j.fuel.2020.118786

[17] HOTH, A., KOLODZIEJ, C.P., ROCKSTROH, T. et al. Combustion characteristics of PRF and TSF ethanol blends with RON 98 in an instrumented CFR engine. SAE Technical Paper 2018-01-1672. 2018.

https://doi.org/10.4271/2018-01-1672
[18] HUANG, G., LI, Z., ZHAO, W. et al. Effects of fuel injection strategies on combustion and emissions of intelligent charge compression ignition (ICCI) mode fueled with methanol and biodiesel. Fuel. 2020, 274, 117851. https://doi.org/10.1016/j.fuel.2020.117851.

[19] HUANG, Y., HONG, G., HUANG, R. Numerical investigation to the dual-fuel spray combustion process in an ethanol direct injection plus gasoline port injection (EDI+GPI) engine. Energy Conversion and Management. 2015, 92, 275-286. https://doi.org/10.1016/j.enconman.2014.12.064

[20] JI, C., WANG, S. Effect of hydrogen addition on combustion and emissions performance of a spark ignition gasoline engine at lean conditions. International Journal of Hydrogen Energy. 2009, 34(18), 7823-7834. https://doi.org/10.1016/j.ijhydene.2009.06.082

[21] JWA, K., NAM, V.D., SETIAWAN, A. et al. Experimental study of the ignition delay of gasoline/biodiesel blends using a rapid compression expansion machine. Energy Procedia. 2019, 158, 655-660, https://doi.org/10.1016/j.egypro.2019.01.178

[22] KALWAR A., SINGH, A.P., AGARWAL, A.K. Utilization of primary alcohols in dual-fuel injection mode in a gasoline direct injection engine. Fuel. 2020, 276, 118068.

https://doi.org/10.1016/j.fuel.2020.118068

[23] KANG, R., ZHOU, L., HUA, J. et al. Experimental investigation on combustion characteristics in dual-fuel dual-injection engine. Energy Conversion and Management. 2019, 181, 1525. https://doi.org/10.1016/j.enconman.2018.11.057

[24] KARAVALAKIS, G., SHORT, D., VU, D. et al. A complete assessment of the emissions performance of ethanol blends and iso-butanol blends from a fleet of nine PFI and GDI vehicles. SAE International Journal of Fuels and Lubricants. 2015, 8(2). https://doi.org/10.4271/2015-01-0957

[25] LATA, D.B., MISRA, A., MEDHEKAR, S. Investigations on the combustion parameters of a dual fuel diesel engine with hydrogen and LPG as secondary fuels. International Journal of Hydrogen Energy. 2011, 36(21), 13808-13819. https://doi.org/10.1016/j.ijhydene.2011.07.142

[26] LEE, J., CHU, S., MIN, K. et al. Classification of diesel and gasoline dual-fuel combustion modes by the analysis of heat release rate shapes in a compression ignition engine. Fuel. 2017, 209, 587-597. https://doi.org/10.1016/j.fuel.2017.07.067

[27] LI, H., LI, C., MA, X. et al. Numerical study of DMF and gasoline spray and mixture preparation in a GDI engine. SAE Technical Paper 2013-01-1592. 2013. https://doi.org/10.4271/2013-01-1592

[28] LIU, H., WANG, Z., WANG, J. Methanol-gasoline DFSI (dual-fuel spark ignition) combustion with dual-injection for engine knock suppression. Energy. 2014, 73, 686-693. https://doi.org/10.1016/j.energy.2014.06.072

[29] LIU, X., SRNA, A., YIP, H.L. et al. Performance and emissions of hydrogen-diesel dual direct injection (H2DDI) in a single-cylinder compression-ignition engine. International Journal of Hydrogen Energy. 2021, 46(1), 1302-1314. https://doi.org/10.1016/j.ijhydene.2020.10.006

[30] LONG, W., LI, B., CAO, J. et al. Effects of dual-direct injection parameters on performance of fuel Jet Controlled Compression Ignition mode on a high-speed light duty engine. Fuel. 2019, 235, 658-669. https://doi.org/10.1016/j.fuel.2018.08.043

[31] MITUKIEWICZ, G., DYCHTO, R., LEYKO, J. Relationship between LPG fuel and gasoline injection duration for gasoline direct injection engines. Fuel. 2015, 153, 526-534. https://doi.org/10.1016/j.fuel.2015.03.033 
[32] MORENO, F., MUÑOZ, M., ARROYO, J. et al. Efficiency and emissions in a vehicle spark ignition engine fueled with hydrogen and methane blends. International Journal of Hydrogen Energy. 2012, 37(15), 11495-11503.

https://doi.org/10.1016/j.ijhydene.2012.04.012

[33] NAYAK, V., RASHMI, G.S., CHITRAGAR, P. et al. Combustion characteristics and cyclic variation of a LPG fuelled MPFI four cylinder gasoline engine. Energy Procedia. 2016, 90, 470-480.

https://doi.org/10.1016/j.egypro.2016.11.214

[34] NING, L., DUAN, Q., KOU, H. et al. Parametric study on effects of methanol injection timing and methanol substitution percentage on combustion and emissions of methanol/diesel dual-fuel direct injection engine at full load. Fuel. 2020, 279, 118424. https://doi.org/10.1016/j.fuel.2020.118424

[35] ROTH, P., YANG, J., PENG, W. et al. Intermediate and high ethanol blends reduce secondary organic aerosol formation from gasoline direct injection vehicles. Atmospheric Environment. 2020, 220, 117064. https://doi.org/10.1016/j.atmosenv.2019.117064

[36] SAITEJA, P., ASHOK, B. A critical insight review on homogeneous charge compression ignition engine characteristics powered by biofuels. Fuel. 2021, 285, 119202,

https://doi.org/10.1016/j.fuel.2020.119202

[37] SCHLATTER, S., SCHNEIDER, B., WRIGHT, Y.M. et al. $\mathrm{N}$-heptane micro pilot assisted methane combustion in a rapid compression expansion machine. Fuel. 2016, 179, 339-352, https://doi.org/10.1016/j.fuel.2016.03.006

[38] SERRANO, D., OBIOLS, J., LECOINTE, B. Optimization of dual fuel diesel-methane operation on a production passenger car engine - thermodynamic analysis. SAE Technical Paper 2013-01-2505. 2013. https://doi.org/10.4271/2013-01-2505

[39] SUN, P., LIU, Z., YU, X. et al. Experimental study on heat and exergy balance of a dual-fuel combined injection engine with hydrogen and gasoline. International Journal of Hydrogen Energy. 2019, 44(39), 22301-22315.

https://doi.org/10.1016/j.ijhydene.2019.06.149

Prof. Ireneusz Pielecha, DSc., DEng. - Faculty of Civil and Transport Engineering, Poznan University of Technology.

e-mail: ireneusz.pielecha@put.poznan.pl
[40] SZYBIST, J., FOSTER, M., MOORE, W.R. et al. Investigation of knock limited compression ratio of ethanol gasoline blends. SAE Technical Paper 2010-01-0619. 2010. https://doi.org/10.4271/2010-01-0619

[41] TIAN, Z., ZHEN, X., WANG, Y. et al. Combustion and emission characteristics of n-butanol-gasoline blends in SI direct injection gasoline engine. Renewable Energy. 2020, 146, 267-279. https://doi.org/10.1016/j.renene.2019.06.041

[42] WINDSOR, H. One car - two gas tanks. Popular Mechanics. 1948.

[43] XU, G., KOTZAGIANNI, M., KYRTATOS, P. et al. Experimental and numerical investigations of the unscavenged prechamber combustion in a rapid compression and expansion machine under engine-like conditions. Combustion and Flame. 2019, 204, 68-84. https://doi.org/10.1016/j.combustflame.2019.01.025

[44] XU, Y., ZHANG, Y., GONG, J. et al. Combustion behaviours and emission characteristics of a retrofitted NG/gasoline duelfuel SI engine with various proportions of NG-gasoline blends. Fuel. 2020, 266, 116957. https://doi.org/10.1016/j.fuel.2019.116957

[45] YOU, J., LIU, Z., WANG, Z. et al. Impact of natural gas injection strategies on combustion and emissions of a dual fuel natural gas engine ignited with diesel at low loads. Fuel. 2020, 260, 116414.

https://doi.org/10.1016/j.fuel.2019.116414

[46] YÜKSEL, F., CEVIZ, M.A. Thermal balance of a four stroke SI engine operating on hydrogen as a supplementary fuel. Energy. 2003, 28(11), 1069-1080. https://doi.org/10.1016/s0360-5442(03)00090-2

[47] ZHAO, W., LI, Z., HUANG, G. et al. Experimental investigation of direct injection dual fuel of n-butanol and biodiesel on intelligent charge compression ignition (ICCI) combustion mode. Applied Energy. 2020, 266, 114884. https://doi.org/10.1016/j.apenergy.2020.114884

Maciej Sidorowicz, DEng. - AC S.A., Bialystok, Poland.

e-mail:maciej.sidorowicz@ac.com.pl
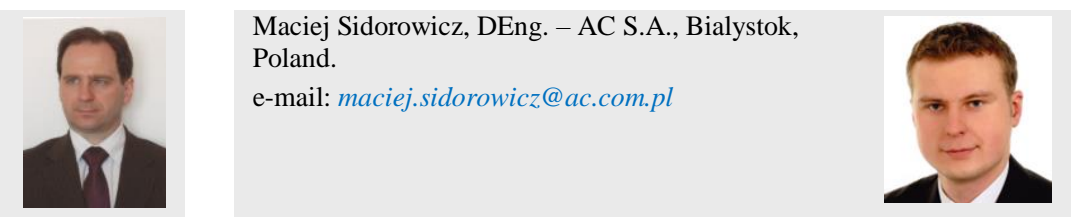